\title{
Foundational elements of communication in health and medicine: avenues for strengthening the marketing communications mix
}

\author{
James K. Elrod ${ }^{1}$ and John L. Fortenberry Jr. ${ }^{1,2^{*}}$
}

\begin{abstract}
Background: When one thinks of opportunities to engage patients, the marketing communications mix often is the first thing that comes to mind. Its five components of advertising, personal selling, sales promotion, public relations, and direct marketing represent tried and true pathways for establishing productive dialogues with customers of healthcare institutions. But in formulating and deploying the marketing communications mix, health and medical establishments must not neglect foundational elements which play vital communicative roles, impacting the perspectives of patients and influencing associated patronage.

Discussion: Many things communicate on behalf of healthcare organizations, including the people employed by them, the places in which they deliver services, and the brands that represent them. As foundational elements of communication, these must be addressed prior to formulating the marketing communications mix, as they influence and impact an institution's entire communicative potential. Their initial development, however, is just the beginning, as these elements must be managed and maintained continually over the course of organizational life. This article profiles foundational elements of communication and discusses their importance in healthcare marketing, generally, and marketing communications, specifically, providing useful insights for maximizing communicative synergies.
\end{abstract}

Conclusions: Given the importance of engaging current and prospective patients, healthcare establishments must take steps to ensure exceptional prowess in this area, with communicative skills and abilities being of paramount importance. Proficient deployment of the marketing communications mix is essential, but healthcare providers must also be certain to direct attention toward foundational elements, ensuring that given institutions realize their full communicative potential.

Keywords: Marketing, Marketing communications, Promotion, Hospitals, Healthcare

\footnotetext{
* Correspondence: john.fortenberry@lsus.edu

'Willis-Knighton Health System, 2600 Greenwood Road, Shreveport, LA

71103, USA

2LSU Shreveport, 1 University Place, Shreveport, LA 71115, USA
}

(c) The Author(s). 2020 Open Access This article is licensed under a Creative Commons Attribution 4.0 International License, which permits use, sharing, adaptation, distribution and reproduction in any medium or format, as long as you give appropriate credit to the original author(s) and the source, provide a link to the Creative Commons licence, and indicate if changes were made. The images or other third party material in this article are included in the article's Creative Commons licence, unless indicated otherwise in a credit line to the material. If material is not included in the article's Creative Commons licence and your intended use is not permitted by statutory regulation or exceeds the permitted use, you will need to obtain permission directly from the copyright holder. To view a copy of this licence, visit http://creativecommons.org/licenses/by/4.0/ The Creative Commons Public Domain Dedication waiver (http://creativecommons.org/publicdomain/zero/1.0/) applies to the data made available in this article, unless otherwise stated in a credit line to the data. 


\section{Background}

Health and medical establishments have intensive needs to communicate with current and prospective patients and, in their efforts to connect with their desired audiences, they often turn to the marketing communications mix [1-5]. Classically illustrated, the marketing communications mix contains five principal avenues of communication; namely, advertising (i.e., the paid use of mass media to deliver messages), personal selling (i.e., the use of sales agents to personally deliver messages), sales promotion (i.e., the use of incentives, such as contests and free giveaways, to encourage patronage), public relations (i.e., the use of publicity and other unpaid promotional methods to deliver messages), and direct marketing (i.e., the delivery of messages via mail, the Internet, and similar routes directly to consumers) $[2,6]$. Healthcare organizations evaluate each option and select one or more believed to be most capable of reaching target audiences, all for the purpose of enticing patronage or compelling some other form of meaningful exchange $[2,7]$.

But in seeking to engage patients via the components of the marketing communications mix, healthcare establishments must take care to ensure that they do not neglect the bigger communicative picture. In some shape, form, or fashion, virtually everything communicates [2, $6,8-12]$. A healthcare facility's brand, the care of its buildings and grounds, the state of its service environment, the presentation and conduct of its staff members, and so on convey volumes of information to others, crucially impacting the perspectives of patients and heavily influencing their patronage decisions $[2,6,8,13-16]$. Such communicative potential is evident from even casual observation, as Figs. 1 and 2, profiling sights and scenes in and around Willis-Knighton Health System, demonstrate. Positive attention directed toward foundational elements affords communicative bedrock; a solid platform for launching components of the marketing communications mix. If addressed improperly, however, no amount of advertising, personal selling, public relations, or any other form of promotion can make up for associated deficiencies, ultimately diminishing opportunities to engage and acquire patients.

While addressing institutional communicators might seem obvious, the rush to telegraph information to outside parties via the marketing communications mix sometimes can cloud priorities, ultimately harming the overall communicative potential of given health and medical establishments $[2,6]$. To help ensure that
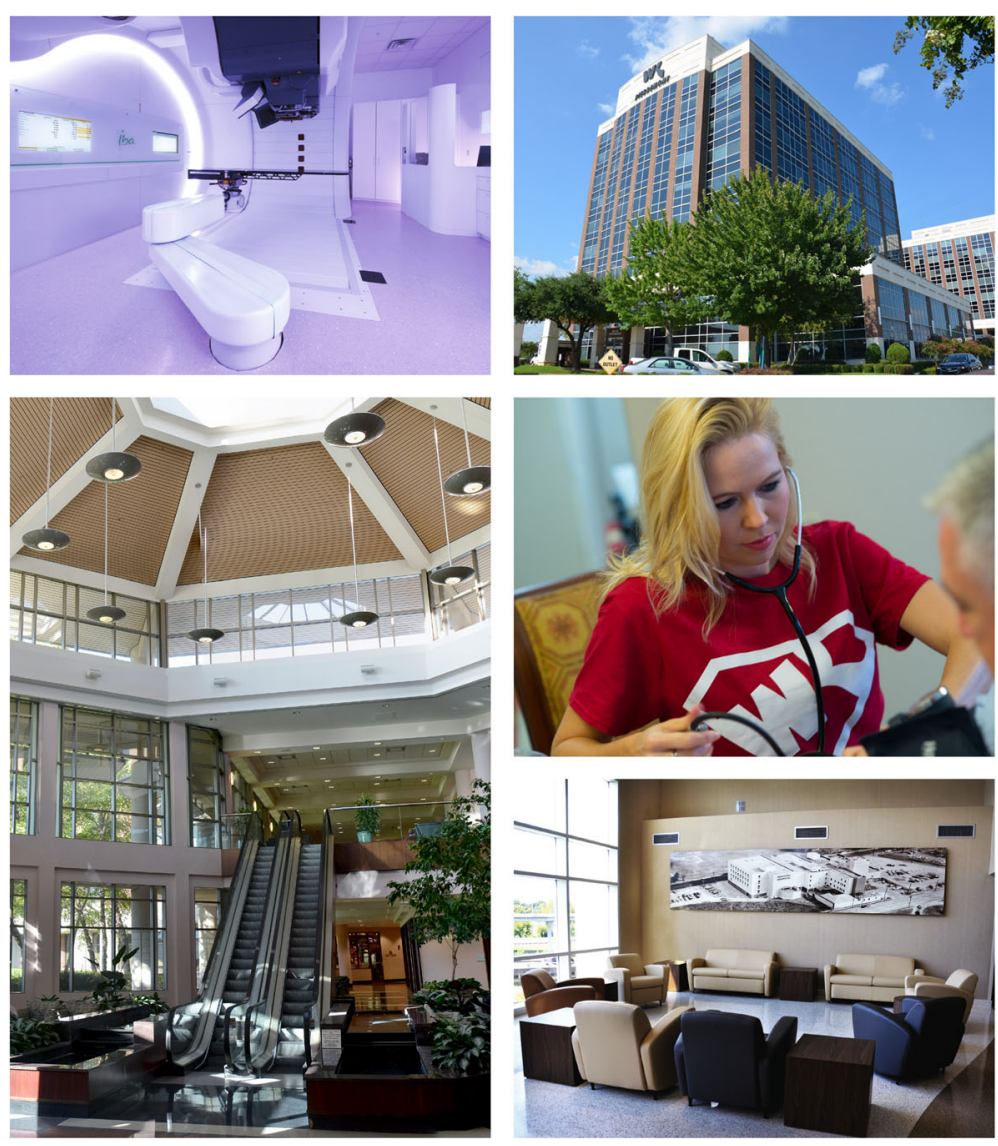

Fig. 1 Sights and scenes from Willis-Knighton Health System demonstrating the communicative potential of people, places, and things 

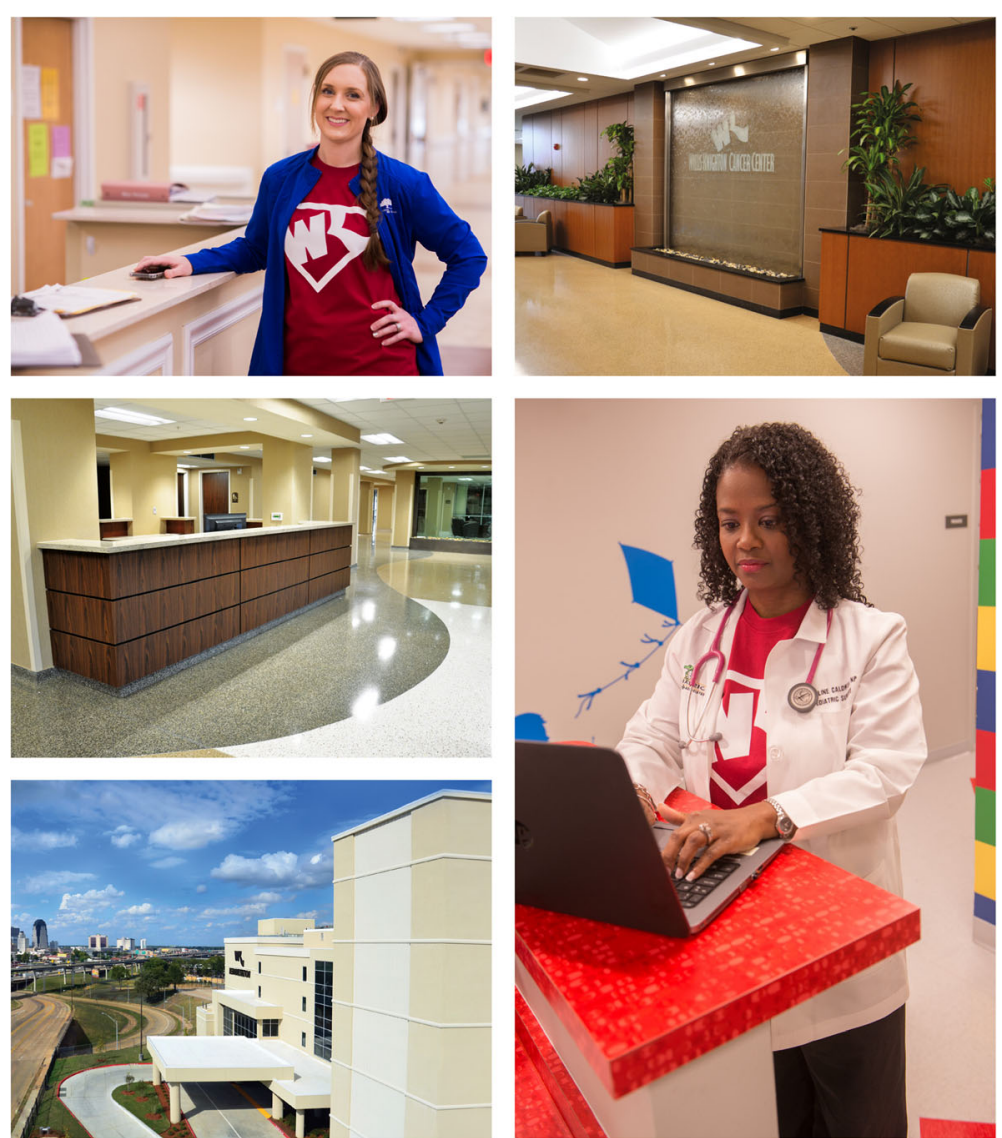

Fig. 2 More sights and scenes from Willis-Knighton Health System demonstrating the communicative potential of people, places, and things

healthcare providers do not lose focus in their quests to proficiently engage patients, this article profiles foundational elements of communication and discusses their importance in healthcare marketing, generally, and marketing communications, specifically, providing useful insights for maximizing communicative synergies.

\section{Definition and overview}

Foundational elements of communication can be described as things that project information to outside parties, but fall outside of the components of the traditional marketing communications mix. Needless to say, this covers significant territory, with these elements including virtually anything and everything that a patient can be exposed to when circulating in or around given healthcare establishments (e.g., adequacy of parking, helpfulness of signage, courtesy of personnel, depth and breadth of services, availability of value-added amenities, comfort of accommodations, quality of food). Viewed through the lens of marketing, these foundational elements represent cornerstones of communication, as they influence conveyances expressed through advertising, personal selling, sales promotion, public relations, and direct marketing $[2,13,15]$. These institutional communicators must be addressed proficiently in advance of formal marketing communications initiatives, ensuring that when prospects are drawn to given healthcare establishments, their expectations built up by deployments of the marketing communications mix are realized. Far from being a static activity, such promotions-critical elements must be managed and maintained continually over the course of organizational life in order to achieve the best marketing communications outcomes [2, 8, 17-21].

Over its many decades of service, Willis-Knighton Health System has never lost sight of the critical need to successfully communicate with audiences. Based in Shreveport, Louisiana and situated in the heart of an area known as the Ark-La-Tex where the states of Arkansas, Louisiana, and Texas converge, Willis-Knighton Health System holds market leadership in its served region where it delivers comprehensive health and wellness services through multiple hospitals, numerous general and specialty medical clinics, an all-inclusive retirement community, and more. The system's achievement of market leadership is attributed, in part, to communications prowess, permitting Willis-Knighton Health System to effectively engage current and prospective patients, evoking interest and attention, ultimately 
leading to burgeoning patient volume and customer loyalty $[1,8,14]$. In its pursuit of excellence in formulating and implementing the marketing communications mix, Willis-Knighton Health System has remained mindful of all-important foundational elements of communication which influence and impact aggregate communicative potential and performance $[8,13,14]$. These institutional communicators-categorized per Willis-Knighton Health System's typology as people, places, and things-are described below.

\section{People}

In many respects, the employees and other personnel serving on behalf of health and medical facilities collectively constitute the most notable communicator for their given institutions. As service entities, interactions between staff members and customers are frequent and intensive, elevating needs for healthcare establishments to ensure that their representatives perform competently and present themselves professionally. Appearance is especially important, meaning that everything from grooming to attire should be in order, with formal dress codes being essential to ensure the conveyance of desirable images to audiences.

Actions also are vital. Beyond conducting assigned duties and responsibilities proficiently, customer service skills are critical, with formal training programs and related initiatives being most helpful in compelling proper mannerisms and behaviors which patients and other parties will find appealing, further reinforcing desired images. Additional conveyances apprising employees of major strategic initiatives, too, are helpful in fostering the communicative potential of staff members. For example, Willis-Knighton Health System actively informs employees of its marketing communications campaigns prior to launch, introducing them to these new initiatives via educational seminars. The institution even holds celebratory launch events, handing out T-shirts, bumper stickers, and related thematic gifts to build employee excitement, morale, and pride. This investment yields educated, informed, and motivated employees, fostering ambassadorship and its associated communicative benefits.

Although people-related matters are well outside of marketing communications, personnel clearly impact a healthcare institution's ability to attract and engage audiences, thus warranting intensive efforts to ensure that they convey positive images. If this can be arranged, then audiences presenting at healthcare establishments, courtesy of advertising and other outward marketing communications, will be greeted by staff members capable of reinforcing their initial patronage decisions, setting the stage for enduring patient relationships and loyalty $[8,15,16]$.

\section{Places}

First impressions are powerful and enduring, with the state of health and medical service environments arguably presenting the initial opportunity for customers to form such impressions. On visiting the campuses of given healthcare facilities or even merely driving by them, many things speak to audiences. The attractiveness of buildings, their state of repair, the care of grounds, the adequacy of parking, the helpfulness of signage, and related exterior aspects communicate boldly to current and prospective patients. A quality exterior certainly can foster notions that given establishments are well operated, supporting perspectives that healthcare services might be delivered with just as much care and attention. The same can be said of interior elements, such as the appearance and comfort of waiting areas, the cleanliness of patient rooms and other spaces, the presentation and functionality of furnishings and fixtures, and related items, with observations of attention to detail here naturally being extrapolated by audiences to other areas of operation.

Since place-related matters indeed have the potential to impact the patronage decisions of patients, healthcare providers must direct extensive attention toward designing and maintaining exterior and interior features to ensure that they match the quality of care provided by given healthcare organizations. Willis-Knighton Health System, for example, invests heavily in the design and upkeep of its buildings and servicescapes to ensure that they are appealing, properly representing the care delivered by the institution. Failures here will erode patient acquisition potential and thwart even carefully devised and successful marketing communications campaigns. However, proper investments and attention directed toward place-related attributes will work synergistically with excellent marketing communications deployments to attract and capture all-important patient volume $[8,15,16]$.

\section{Things}

Items not falling in people and places categories are ideal for situating in the things category, permitting the typology to accommodate most any foundational element of communication. The method and manner for populating this category is up to given healthcare institutions. Some establishments might, for example, place technology here, whereas others might consider technology to be a component of servicescapes, making it better suited as a place matter. While such decisions rest with given healthcare entities, one particular item is especially well suited for this category: brands.

Brands are names, logos, slogans, and related elements of identity used by institutions and their product offerings for the purpose of conveying desired images to target audiences. Brands present imagery designed to 
resonate with customers, enticing patronage, and they also permit audiences to distinguish institutions and their products from competitive offerings, facilitating product differentiation. As brands are featured in virtually every marketing communication forwarded by healthcare entities, care must be taken to ensure that associated identities are meaningful and relevant, as this will have a direct impact on advertising, public relations, and other components of the marketing communications mix. This knowledge led Willis-Knighton Health System to direct extensive resources toward branding, ultimately affording one of the most widely recognized logos in the marketplace. Once thoughtfully prepared, brand-related efforts do not cease; they continue indefinitely as a means of ensuring that formulated identities remain on point. Willis-Knighton Health System, for example, reviews its brand identity on a regular basis, making alterations as needed to ensure desired applicability and impact $[8,13]$. While the things category can encompass myriad elements, as deemed suitable by given healthcare establishments, brands certainly should not be overlooked as a key institutional communicator upon which forthcoming marketing communications plans are built.

\section{Operational reflections}

As for operationalizing this typology, given that these elements are foundational in nature and impact the potential of advertising, personal selling, direct marketing, and other promotional deployments, Willis-Knighton Health System recommends conducting readiness assessments in advance of launching marketing communications campaigns. Such readiness assessments involve comprehensively examining the healthcare service or services to be featured in forthcoming campaigns to ensure that audiences responding to given appeals are met with people, places, and things that foster satisfaction and facilitate patronage. These readiness assessments usually involve comprehensive walk-throughs in and around healthcare facilities, typically conducted by institutional leaders, to ensure that service environments are appealing and inviting, examining, for example, the cleanliness of the premises, the adequacy of parking and directional signage, the ease of scheduling appointments, the appearance and professionalism of employees, and so on.

Campaign readiness assessments sometimes are enhanced by the use of mystery shoppers hired to pose as patients, visit designated service environments, make associated inquiries, and report their findings, affording helpful external perspectives which might reveal improvement opportunities otherwise overlooked by personnel. Oversights can and do occur, given institutional and environmental complexities, warranting preventive measures to ensure top performance. The campaign readiness assessment is one such preventive measure that offers health and medical providers one final opportunity before promotions ensue to perfect service experiences, something which can bolster the abilities of institutions to capture patronage and generate positive word-of-mouth communications from satisfied customers. What's more, implementation is relatively burden-free, with perhaps its simplest application involving completion of a checklist prior to the authorization of marketing communications campaigns.

\section{Conclusions}

Given the importance of engaging current and prospective patients, healthcare establishments must take steps to ensure exceptional prowess in this area, with communicative skills and abilities being of paramount importance. Proficient deployment of the marketing communications mix is essential, but healthcare providers must also be certain to direct attention toward foundational elements that speak boldly on behalf of healthcare institutions, influencing and impacting outwardly-directed marketing communications. Categorized conveniently, comprehensively, and memorably as people, places, and things, these foundational elements must be perfected in order to allow the components of the marketing communications mix to be deployed in a manner to realize their full communicative potential.

\section{Acknowledgments \\ A special note of thanks is extended to Marilyn Joiner, Darrell Rebouche, and the greater Willis-Knighton Health System family for their helpful assistance} throughout the development and publication of this article.

\section{About this supplement \\ This article has been published as part of BMC Health Services Research Volume 20 Supplement 1, 2020: Marketing communications in health and medicine: perspectives from Willis-Knighton Health System. The full contents of the supplement are available online at http://bmchealthservres.biomed- central.com/articles/supplements/volume-20-supplement-1.}

\section{Authors' contributions}

The authors jointly developed the submitted manuscript, with each performing critical roles from early conceptualization through to the production of the full manuscript. The manuscript resulted from a collaborative effort. Both authors read and approved the final manuscript.

\section{Authors' information}

JKE is President and Chief Executive Officer of Shreveport, Louisiana-based Willis-Knighton Health System, the region's largest provider of healthcare services. With over 55 years of service at the helm of the institution, JKE is America's longest-tenured hospital administrator. A fellow in the American College of Healthcare Executives and honoree as a Louisiana Legend by Friends of Louisiana Public Broadcasting, he holds a bachelor's degree in business administration from Baylor University, a master's degree in hospital administration from Washington University School of Medicine, and an honorary doctorate of science and humane letters from Northwestern State University of Louisiana. He is the author of Breadcrumbs to Cheesecake, a book which chronicles the history of Willis-Knighton Health System.

JLF Jr. is Chair of the James K. Elrod Department of Health Administration, James K. Elrod Professor of Health Administration, and Professor of Marketing in the College of Business at LSU Shreveport where he teaches a variety of courses in both health administration and marketing. He holds a BBA in marketing from the University of Mississippi; an MBA from Mississippi College; a PhD in public administration and public policy, with

concentrations in health administration, human resource management, and 
organization theory, from Auburn University; and a PhD in business administration, with a major in marketing, from the University of Manchester in the United Kingdom. He is the author of six books, including Health Care Marketing: Tools and Techniques, 3rd Edition, published by Jones and Bartlett Learning. JLF Jr. also serves as Vice President of Marketing Strategy and Planning at Willis-Knighton Health System.

\section{Funding}

Article processing charges were funded by Willis-Knighton Health System.

\section{Availability of data and materials}

Not applicable.

\section{Ethics approval and consent to participate}

Not applicable.

\section{Consent for publication}

Figures 1 and 2 are published with permission of Willis-Knighton Health System. All required approvals for publication were obtained.

\section{Competing interests}

JKE and JLF Jr. are both employed with Willis-Knighton Health System.

\section{Published: 15 September 2020}

\section{References}

1. Elrod JK, Fortenberry $J \mathrm{~L} J \mathrm{~J}$. Catalyzing marketing innovation and competitive advantage in the healthcare industry: the value of thinking like an outsider. BMC Health Serv Res. 2018;18(Suppl 3):922.

2. Fortenberry $J \mathrm{~L} J \mathrm{~J}$. Health care marketing: tools and techniques. 3rd ed. Sudbury: Jones and Bartlett; 2010.

3. Berkowitz E. Essentials of health care marketing. 4th ed. Burlington: Jones and Bartlett; 2017.

4. Thomas RK. Marketing health services. 3rd ed. Chicago: Health Administration Press; 2014.

5. Kotler P, Shalowitz J, Stevens RJ. Strategic marketing for health care organizations: building a customer-driven health system. San Francisco: Jossey-Bass; 2008.

6. Fortenberry JL Jr. Cases in health care marketing. Sudbury: Jones and Bartlett; 2011.

7. Fortenberry JL Jr. Nonprofit marketing. Burlington: Jones and Bartlett; 2013.

8. Elrod JK. Breadcrumbs to cheesecake. Shreveport: R\&R Publishers; 2013.

9. Schiavo R. Health communication: from theory to practice. 2nd ed. San Francisco: Jossey-Bass; 2014.

10. Parvanta CF, Nelson DE, Harner RN. Public health communication: critical tools and strategies. Burlington: Jones and Bartlett; 2018.

11. Kotler P, Keller KL. Marketing management. 14th ed. Upper Saddle River: Prentice Hall; 2012

12. Perreault WD Jr, Cannon JP, McCarthy EJ. Basic marketing: a marketing strategy planning approach. 19th ed. New York: McGraw-Hill; 2014.

13. Elrod JK, Fortenberry $J \mathrm{~J} J$ r. Driving brand equity in health services organizations: the need for an expanded view of branding. BMC Health Serv Res. 2018;18(Suppl 3):924.

14. Elrod JK, Fortenberry JL Jr. Formulating productive marketing communications strategy: a major health system's experience. BMC Health Serv Res. 2018;18(Suppl 3):926.

15. Fortenberry $J \mathrm{~J}$ r, McGoldrick PJ. Internal marketing: a pathway for healthcare facilities to improve the patient experience. Int J Healthc Manag. 2016;9(1):28-33

16. Elrod JK, Fortenberry $\mathrm{JL} J \mathrm{~J}$. Am I seeing things through the eyes of patients? An exercise in bolstering patient attentiveness and empathy. BMC Health Serv Res. 2018;18(Suppl 3):929.

17. Moriarty S, Mitchell N, Wood C, Wells WD. Advertising and IMC: principles and practice. 11th ed. New York: Pearson; 2019.

18. Andrews JC, Shimp TA. Advertising, promotion, and other aspects of integrated marketing communications. 10th ed. Boston: Cengage; 2018

19. Ogilvy D. Ogilvy on advertising. New York: Random House; 1985.

20. Feinberg D. Why advertise ... and why not? Mark Health Serv. 2011;31(2):3-5.

21. Tellis GJ. Effective advertising: understanding when, how, and why advertising works. Thousand Oaks: Sage; 2004.

\section{Publisher's Note}

Springer Nature remains neutral with regard to jurisdictional claims in published maps and institutional affiliations.
Ready to submit your research? Choose BMC and benefit from:

- fast, convenient online submission

- thorough peer review by experienced researchers in your field

- rapid publication on acceptance

- support for research data, including large and complex data types

- gold Open Access which fosters wider collaboration and increased citations

- maximum visibility for your research: over $100 \mathrm{M}$ website views per year

At BMC, research is always in progress.

Learn more biomedcentral.com/submissions 